\title{
Metal Halide and Pseudohalide Complexes in Dimethylsulfoxide Solution. X. Equilibrium and Enthalpy Measurements on Halide Systems of Zinc(II), Cadmium(II) and Mercury(II) in $0.1 \mathrm{M}$ Ammonium Perchlorate
}

\author{
STEN AHRLAND, ${ }^{\mathrm{a}}$ NILS-OLOF BJÖRK ${ }^{\mathrm{b}}$ and INGMAR PERSSON ${ }^{\mathrm{a}}$
}

a Inorganic Chemistry 1, Chemical Center, University of Lund, P. O. Box 740, S-220 07 Lund 7, Sweden and

${ }^{b}$ Alfa-Laval AB, P.O. Box 1721, S-220 01 Lund, Sweden

The thermodynamics of the formation of zinc(II) bromide, cadmium(II) chloride, bromide and iodide, and mercury(II) bromide complexes in dimethyl sulfoxide (DMSO) have been studied in a $0.1 \mathrm{M}$ ammonium perchlorate medium at $25^{\circ} \mathrm{C}$. The stability constants have been determined potentiometrically and, except for the mercury(II) bromide, also calorimetrically, and the enthalpy changes calorimetrically. The complexes are more stable in the present medium than in the $1 \mathrm{M}$ ammonium perchlorate employed previously. The overall enthalpy changes are less favourable than in $1 \mathrm{M}$ ammonium perchlorate, but the overall entropy gains are considerably more favourable. The coordination changes take place at the same steps as in $1 \mathrm{M}$ medium, except for the zinc(II) bromide. In this system, the switch from octahedral to tetrahedral coordination moves from the first to the second stepas the concentration of $\mathrm{NH}_{4}^{+}$is decreased from 1 to $0.1 \mathrm{M}$.

The thermodynamics of zinc(II), cadmium(II) and mercury(II) halide and thiocyanate complex formation in the aprotic solvent dimethylsulfoxide (DMSO) have previously been investigated for the ionic medium $1 \mathrm{M}$ ammonium perchlorate. ${ }^{1-5}$ It is of interest to investigate some of these systems at a lower concentration of ammonium perchlorate, in order to study the effects of a considerable quantitative change of the medium. The cadmium(II) halides have been chosen in order to examine how complexes formed by ligands of gradually changing bonding chacteristics are influenced. By investigat- ing also the zinc(II) and mercury(II) bromide systems, the effect on complexes of metal ions coordinating via bonds of different types can also be studied. The stability constants of the zinc(II) and cadmium(II) complexes have been determined both potentiometrically, by means of amalgam electrodes, and calorimetrically. Simultaneous determinations of the stabilities, i.e. the free energy changes, and the heats of reaction by calorimetric measurements are possible only under certain conditions ${ }^{6}$ which are, however, met for these systems. ${ }^{2,4}$ For mercury (II) bromide they are not, however, so constants of this system have only been determined potentiometrically, by means of the mercury electrode.

\section{EXPERIMENTAL}

Chemicals. The solid solvates [Zn(DMSO $\left.)_{6}\right]$ $\left(\mathrm{ClO}_{4}\right)_{2},\left[\mathrm{Cd}(\mathrm{DMSO})_{6}\right]\left(\mathrm{ClO}_{4}\right)_{2}$ and $\mathrm{Hg}\left(\mathrm{ClO}_{4}\right)_{2}$ -4DMSO, the ligand solutions and the amalgams used were prepared and analyzed as described previously. ${ }^{1,7-9}$

Potentiometric measurements. The procedures used in the potentiometric measurements have been described elsewhere. ${ }^{1,3,5}$ As reference electrode, the very stable and reproducible cadmium amalgam electrode has been used. The zinc and cadmium amalgam electrodes and the mercury electrode all follow Nernst's law. Their standard potentials for the medium used have been determined previously. ${ }^{10}$ Three different values of the initial metal ion concentration were used in the potentiometric titrations, and each titration was repeated at least twice. The reproducibility was in 
general better than $0.3 \mathrm{mV}$ for the mercury(II) bromide and better than $0.4 \mathrm{mV}$ for the zinc(II) and cadmium(II) halides. The emf stayed constant within $0.5 \mathrm{mV}$ for at least $15 \mathrm{~h}$.

The stability constants $\beta_{j}$ were calculated from the potentiometric measurements by the computer program EMK, ${ }^{11}$ or for the reversed titrations used for the mercury(II) bromide system, by a modified version of this program. The formulas used in these programs have been long established. ${ }^{2,13}$

In the zinc and cadmium systems, no experimental values were discarded in the final calculation of $\beta_{\mathrm{j}}$. In the mercury bromide system, certain points had to be omitted, as will be further discussed below.

Calorimetric measurements. The calorimeter and the technique used have been described previously. ${ }^{2,4,5,14,15}$ The calibration constant $\varepsilon_{\mathrm{v}}$ was the same as before. ${ }^{5}$ The heats of dilution were determined by titrations where either the ligand or the central ion solution had been exchanged for pure ionic medium. ${ }^{2,4,5}$ In the mercury(II) bromide system it has, moreover, been possible to determine the heats of dilution of the intermediate complexes $\mathrm{HgBr}^{+}, \mathrm{HgBr}_{2}$ and $\mathrm{HgBr}_{3}^{-}$. These are around 60 , 45 and $30 \%$, respectively, of the heat of dilution of $\mathrm{Hg}^{2+}$. Enthalpy changes and stability constants have been calculated from the calorimetric measurements by the program KALORI. ${ }^{11}$ For the final calculation of the enthalpy changes, the weighted means of the stability constants determined potentiometrically and calorimetrically were used as fixed parameters. Complete experimental data are available from the authors.

Table 1 . The overall stability constants $\left(\beta_{j} / \mathbf{M}^{-j}\right)$ of the zinc(II) bromide complexes in DMSO, ionic medium $0.1 \mathrm{M}$ ammonium perchlorate, at $25^{\circ} \mathrm{C}$. The constants have been determined potentiometrically and calorimetrically; the errors stated refer to three standard deviations. $\mathrm{NP}=$ number of points.

\begin{tabular}{llll}
\hline & Pot. & Cal. & Mean \\
\hline$\beta_{1}$ & $74 \pm 26$ & $71 \pm 57$ & $73 \pm 27$ \\
$\beta_{2}$ & $(1.47 \pm 0.10) \times 10^{5}$ & $(1.57 \pm 0.23) \times 10^{5}$ & $(1.48 \pm 0.11) \times 10^{5}$ \\
$\beta_{3}$ & $(1.47 \pm 0.06) \times 10^{7}$ & $(1.19 \pm 0.48) \times 10^{7}$ & $(1.44 \pm 0.12) \times 10^{7}$ \\
NP & 185 & 181 & \\
\hline
\end{tabular}

Table 2 . The stability constants $\left(\beta_{\mathrm{j}} / \mathrm{M}^{-\mathrm{j}}\right)$ of cadmium(II) chloride, bromide and iodide complexes in DMSO, ionic medium $0.1 \mathrm{M}$ ammonium perchlorate, at $25^{\circ} \mathrm{C}$. The constants have been determined potentiometrically and calorimetrically; the errors refer to three standard deviations.

\begin{tabular}{llll}
\hline & Pot & Cal. & Mean \\
\hline Chloride & & & \\
$\beta_{1}$ & $(2.36 \pm 0.37) \times 10^{4}$ & $(2.22 \pm 0.35) \times 10^{4}$ & $(2.29 \pm 0.25) \times 10^{4}$ \\
$\beta_{2}$ & $(2.49 \pm 1.54) \times 10^{7}$ & $(1.71 \pm 0.54) \times 10^{7}$ & $(1.91 \pm 0.82) \times 10^{7}$ \\
$\beta_{3}$ & $(5.79 \pm 1.05) \times 10^{10}$ & $(5.04 \pm 1.45) \times 10^{10}$ & $(5.48 \pm 0.80) \times 10^{10}$ \\
$\beta_{3}$ & $(1.54 \pm 0.32) \times 10^{13}$ & $(0.88 \pm 0.31) \times 10^{13}$ & $(1.21 \pm 0.22) \times 10^{13}$ \\
NP & 105 & 198 & \\
Bromide & & & \\
$\beta_{1}$ & & $4480 \pm 800$ & \\
$\beta_{2}$ & $4960 \pm 250$ & $(1.15 \pm 0.72) \times 10^{6}$ & $(1.52 \pm 0.41) \times 10^{6}$ \\
$\beta_{3}$ & $(1.72 \pm 0.38) \times 10^{6}$ & $(2.70 \pm 0.94) \times 10^{9}$ & $(2.87 \pm 0.47) \times 10^{9}$ \\
$\beta_{4}$ & $(2.90 \pm 0.15) \times 10^{9}$ & $1.67 \pm 1.26) \times 10^{11}$ & $(1.94 \pm 0.64) \times 10^{11}$ \\
NP & $(1.97 \pm 0.12) \times 10^{11}$ & & \\
Iodide & 146 & & \\
$\beta_{1}$ & & $330 \pm 75$ & $370 \pm 41$ \\
$\beta_{2}$ & & $(3.24 \pm 2.30) \times 10^{4}$ & $(2.32 \pm 1.28) \times 10^{4}$ \\
$\beta_{3}$ & $386 \pm 31$ & $(1.72 \pm 0.41) \times 10^{7}$ & $(1.58 \pm 0.21) \times 10^{7}$ \\
$\beta_{4}$ & $(1.87 \pm 1.12) \times 10^{4}$ & $(6.07 \pm 4.04) \times 10^{8}$ & $(2.15 \pm 2.02) \times 10^{8}$ \\
NP & $(1.53 \pm 0.21) \times 10^{7}$ & & \\
\hline
\end{tabular}




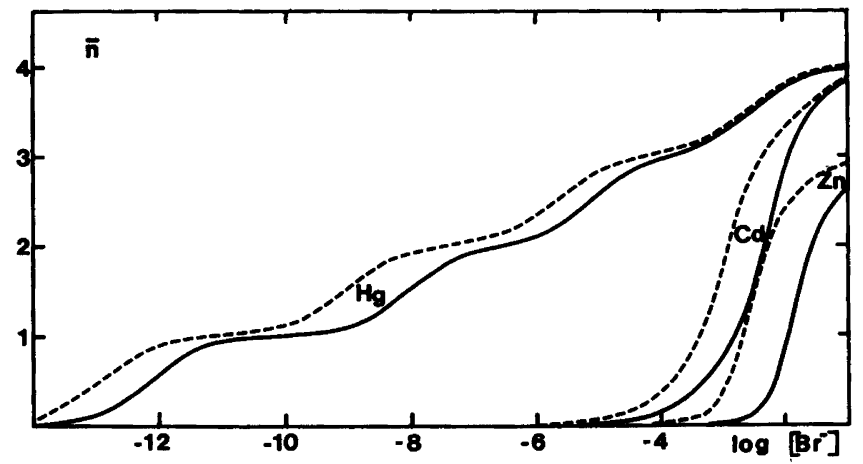

Fig. 1. The complex formation functions of the zinc(II), cadmium(II) and mercury(II) bromide systems in DMSO, ionic media $0.1 \mathrm{M}$ and $1 \mathrm{M}$ ammonium perchlorate (dashed and solid curves, respectively).

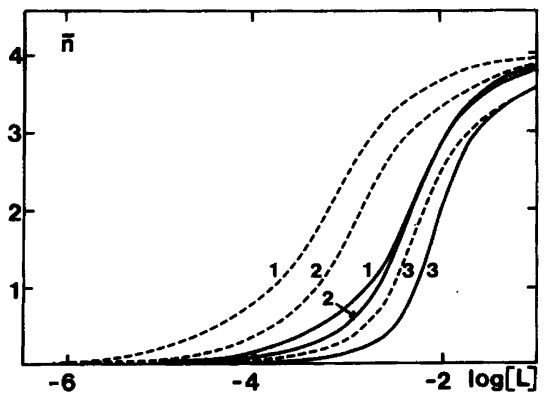

Fig. 2. The complex formation functions of the cadmium(II) halide systems in DMSO, ionic media $0.1 \mathrm{M}$ and $1 \mathrm{M}$ ammonium perchlorate (dashed and solid curves, respectively). Ligands: chloride(1), bromide(2), iodide(3).

\section{MEASUREMENTS AND RESULTS}

Zinc(II) bromide. In the range of central ion and ligand concentrations used in the potentiometric measurements, viz. $2.5 \mathrm{mM} \leq C_{\mathrm{M}} \leq 19.0 \mathrm{Mm}$, and 0 $\leq C_{\mathrm{L}} \leq 75.1 \mathrm{mM}$, respectively, the complex formation is well described by three mononuclear complexes. Four complexes give about the same sum of least squares, but the error of the fourth stepwise constant $K_{4}$ is so large that the last complex remains hypothetical. No polynuclear complexes are formed in the ranges of $C_{\mathrm{M}}$ and $C_{\mathrm{L}}$ investigated. The results are in Table 1.

In the calorimetric measurements, the ranges of $C_{\mathrm{M}}$ and $C_{\mathrm{L}}$ used were $2.6 \mathrm{mM} \leq C_{\mathrm{M}} \leq 16.2 \mathrm{mM}$ and $0 \leq C_{\mathrm{L}} \leq 67.3 \mathrm{mM}$. Also these measurements indicate the formation of three mononuclear complexes.
The values of $\beta_{\mathrm{j}}$ are listed in Table 1 as are the weighted means of the values found by the two methods employed. The complex formation function calculated from the mean constants is plotted in Fig. 1. The means were also used in the final calculation of the values of $\Delta H_{\beta j}^{\circ}$ listed in Table 4. In Fig. 3, the total molar enthalpy change $\Delta h_{\mathrm{v}}$ is plotted as a function of the ligand number $\bar{n}$. The stepwise stability constants $K_{\mathrm{j}}$, their ratios $K_{\mathrm{j}} / K_{\mathrm{j}+1}$, and the thermodynamic functions $\Delta G_{\mathrm{j}}^{\circ}, \Delta H_{\mathrm{j}}^{\circ}$ and $\Delta S_{j}^{\circ}$ of the consecutive steps, calculated from the values of $\beta_{\mathrm{j}}$ and $\Delta H_{\beta \mathrm{j}}$ finally adopted, are collected in Table 6.

Cadmium(II) chloride, bromide and iodide. In the potentiometric measurements, the concentration ranges used for the chloride system were $3.3 \mathrm{mM}$ $\leq C_{\mathrm{M}} \leq 19.6 \mathrm{mM}$ and $0 \leq C_{\mathrm{L}} \leq 54.6 \mathrm{mM}$, for the bromide system $2.3 \mathrm{mM} \leq C_{\mathrm{M}} \leq 19.6 \mathrm{Mm}$ and $0 \leq C_{\mathrm{L}} \leq 66.7 \mathrm{mM}$, and for the iodide system $1.3 \mathrm{mM}$ $\leq C_{\mathrm{M}} \leq 19.6 \mathrm{mM}$ and $0 \leq C_{\mathrm{L}} \leq 75.0 \mathrm{mM}$. Within these ranges, four mononuclear complexes are formed in all the systems. No polynuclear complexes exist, which is not surprising as such complexes are seemingly not formed even in very concentrated solutions. ${ }^{16}$ The values of $\beta_{\mathrm{j}}$ are in Table 2 .

In the calorimetric measurements, the range of concentration of cadmium(II) was $3.2 \mathrm{mM} \leq C_{\mathrm{M}}$ $\leq 19.7 \mathrm{mM}$, of chloride and bromide $0 \leq C_{\mathrm{L}} \leq 59.1$ $\mathrm{mM}$, and of iodide $0 \leq C_{\mathrm{L}} \leq 67.3 \mathrm{mM}$. Also by this method, four mononuclear complexes were found, and the values of $\beta_{j}$ agree quite well with those found potentiometrically (Table 2). From the weighted means of $\beta_{\mathrm{j}}$, see Table 2 , the complex formation curves plotted in Fig. 2 have been calculated, and also the final values of $\Delta H_{\beta \mathbf{j}}^{\circ}$, see 
Table 4. In Fig. $4, \Delta h_{\mathrm{v}}$ is given as a function of $\bar{n}$. The curves of the bromide system have also been entered in Figs. 1 and 3. The constants and thermodynamic functions referring to the consecutive steps are collected in Table 5, and, for the bromide system, also in Table 6.

Mercury(II) bromide. In the reversed titrations performed for this system, the mercury(II) and bromide concentrations were varied in the ranges 2.5 $\mathrm{mM} \leq C_{\mathrm{M}} \leq 13.7 \mathrm{mM}$ and $8.0 \leq C_{\mathrm{L}} \leq 58.3 \mathrm{mM}$. The actual concentration of mercury(II) reacting with bromide was calculated from the equivalence points observed in the titrations and found to be $0.1 \mathrm{mM}$ less than the formal concentration. This agrees with the results obtained earlier in $1 \mathrm{M}$ ammonium perchlorate medium and confirms the conclusion drawn that the discrepancy is due to an impurity in the DMSO, with a very strong affinity for mercury(II). ${ }^{5}$ Experimental points of $\bar{n}<1.66$ could not be made to fit, evidently on account of an incipient formation of mercury(I). These points were discarded. Four mononuclear complexes are found, with constants listed in Table 3. No polynuclear complexes are indicated; no such complexes are, in fact, formed even in much more concentrated solutions of this system. ${ }^{17,18}$ The complex formation function is given in Fig. 1.

Table 3. The stability constants $\left(\beta_{j} / \mathbf{M}^{-\mathrm{j}}\right)$ of the mercury(II) bromide complexes in DMSO, ionic medium $=0.1 \mathrm{M}$ ammonium perchlorate, at $25^{\circ} \mathrm{C}$. The constants have been determined potentiometrically; the errors refer to three standard deviations.

\begin{tabular}{ll}
\hline$\beta_{1}$ & $(8.29 \pm 0.69) \times 10^{12}$ \\
$\beta_{2}$ & $(9.17 \pm 0.78) \times 10^{21}$ \\
$\beta_{3}$ & $(4.20 \pm 0.46) \times 10^{27}$ \\
$\beta_{4}$ & $(1.67 \pm 0.22) \times 10^{30}$ \\
$\mathrm{NP}$ & 361 \\
\hline
\end{tabular}

The calorimetric measurements have been performed in the ranges $3.2 \leq C_{\mathrm{M}} \leq 15.7 \mathrm{mM}$ and $0 \leq C_{\mathrm{L}}$ $\leq 56.6 \mathrm{mM}$. As the function $\Delta h_{\mathrm{v}}$ does not display any marked points of equivalence (Fig. 3), any correction of $C_{\mathrm{M}}$ was neither indicated, nor needed. The smooth course of $\Delta h_{v}$ is due to the fact that the values of $\Delta H_{\mathrm{j}}^{\circ}$ do not differ very much between the consecutive steps (Table 6). The values of $\Delta H_{\beta j}^{\circ}$ are in Table 4, and the quantities calculated for the consecutive steps in Table 6.

\section{DISCUSSION}

In Tables 5 and 6, the equilibrium constants and thermodynamic functions of the consecutive steps, derived from the present measurements in $0.1 \mathrm{M}$ ammonium perchlorate, are compared with those found previously in $1 \mathrm{M}$ ammonium perchlorate. ${ }^{1-5}$

The comparison between the cadmium(II) halide systems in the two media shows (Table 5) that the decrease of the ammonium perchlorate concentration causes a large increase of $K_{\mathrm{j}}$ (roughly ten times) for the chloride complexes and a considerably smaller one for the bromide complexes. For the iodide complexes, a small increase is found for $K_{1}$ and $K_{2}$, while $K_{3}$ and $K_{4}$ even show a slight decrease between the $1 \mathrm{M}$ and the $0.1 \mathrm{M}$ medium. In DMSO, the pattern is thus distinctly different for different halides. In a protic solvent like water, on the other hand, much the same pattern is found for chloride and iodide, at least in sodium perchlorate media, ${ }^{19}$ and this pattern is moreover very similar to that found presently for iodide in DMSO. In these cases, the changes are of the magnitude to be expected as a consequence of the change of the activity conditions accompanying a decrease of the ionic strength, $I$, from $\simeq 1$ to $\simeq 0.1 \mathrm{M}$. Especially for the chloride, but also for the bromide, the changes in DMSO between the two media are larger than expected, however. Most likely, this indicates a

Table 4. Overall enthalpy changes $\left(\Delta H_{\beta j} / \mathrm{kJ} \mathrm{mol}^{-1}\right)$ for the formation of the zinc(II) bromide, cadmium(II) chloride, bromide, iodide and mercury(II) bromide systems in DMSO, ionic medium $0.1 \mathrm{M}$ ammonium perchlorate, at $25^{\circ} \mathrm{C}$. The errors stated refer to three standard deviations.

\begin{tabular}{lcrrrl}
\hline System & \multicolumn{1}{c}{$\mathrm{Zn}^{2+}-\mathrm{Br}^{-}$} & \multicolumn{1}{c}{$\mathrm{Cd}^{2+}-\mathrm{Cl}^{-}$} & \multicolumn{1}{c}{$\mathrm{Cd}^{2+}-\mathrm{Br}^{-}$} & \multicolumn{1}{c}{$\mathrm{Cd}^{2+}-\mathrm{I}^{-}$} & $\mathrm{Hg}^{2+}-\mathrm{Br}^{-}$ \\
\hline$-\Delta H_{\beta^{1}}^{\circ}$ & $-(22.3 \pm 1.7)$ & $4.9 \pm 0.2$ & $0.9 \pm 0.3$ & $-(5.2 \pm 0.3)$ & $20.0 \pm 0.6$ \\
$-\Delta H_{\beta^{2}}$ & $-(42.2 \pm 0.5)$ & $-(7.5 \pm 0.8)$ & $-14.9 \pm 1.4)$ & $-(26.8 \pm 2.6)$ & $44.1 \pm 0.9$ \\
$-\Delta H_{\beta 3}^{\beta^{3}}$ & $-(36.3 \pm 0.5)$ & $-(14.0 \pm 0.3)$ & $-(22.0 \pm 0.4)$ & $-(33.3 \pm 0.5)$ & $68.5 \pm 1.1$ \\
$-\Delta H_{\beta 4}$ & 181 & $1.5 \pm 0.3$ & $-(10.6 \pm 0.6)$ & $-(28.7 \pm 1.4)$ & $85.8 \pm 1.4$ \\
$\mathrm{NP}$ & 198 & 177 & 174 & 219 \\
\hline
\end{tabular}




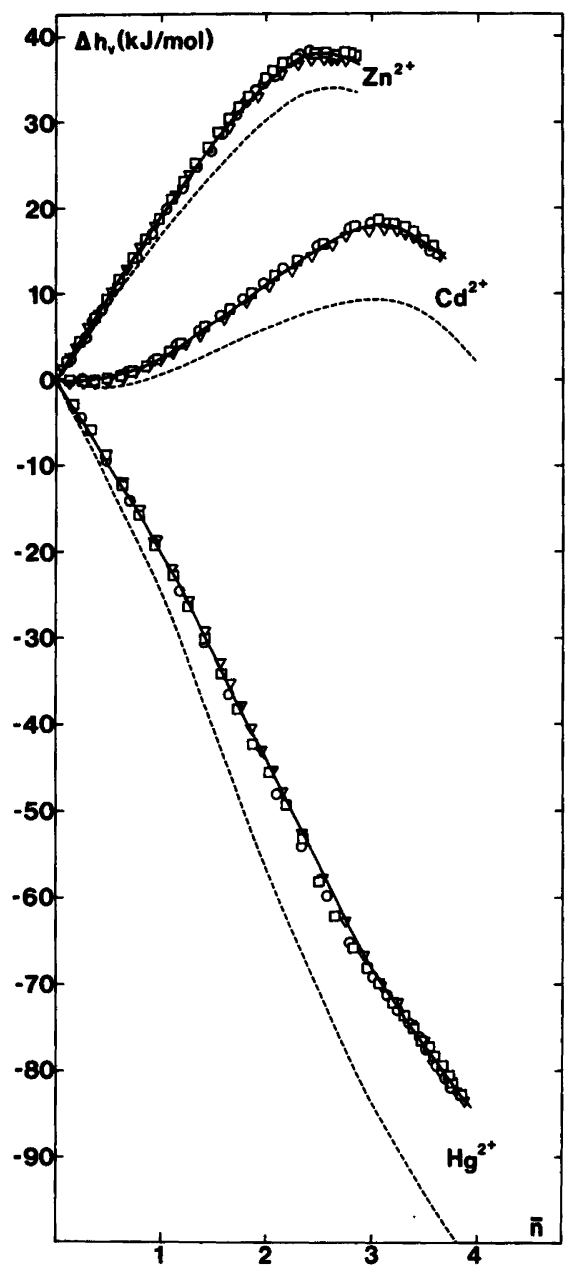

Fig. 3. The total molar enthalpy change $\Delta h_{\mathrm{v}}$ as a function of the ligand number $\bar{n}$ for the zinc(II), cadmium(II) and mercury(II) bromide systems in DMSO at $25^{\circ} \mathrm{C}$. The symbols refer to the present titrations in $0.1 \mathrm{M}$ ammonium perchlorate at the initial concentrations $C_{M}^{\prime}=4(O), 8(\square)$ and $16 \mathrm{mM}$ $(\nabla)$. The curves have been calculated from the values of $\beta_{\mathrm{j}}$ and $\Delta H_{\beta \mathrm{j}}$ obtained in $0.1 \mathrm{M}$ and $1 \mathrm{M}$ ammonium perchlorate (solid and dashed, respectively).

formation in DMSO of complexes between $\mathrm{NH}_{4}^{+}$ and $\mathrm{Cl}^{-}$and, to a lesser extent, between $\mathrm{NH}_{4}^{+}$and $\mathrm{Br}^{-}$. Thus, $\mathrm{NH}_{4} \mathrm{Cl}$ is not at all completely dissosociated in DMSO at concentrations of $\mathrm{NH}_{4}^{+}$as high as $1 \mathrm{M}$, nor is $\mathrm{NH}_{4} \mathrm{Br}^{20}$ On the other hand, $\mathrm{NH}_{4} \mathrm{I}$ probably is, as are also all the sodium halides in water.

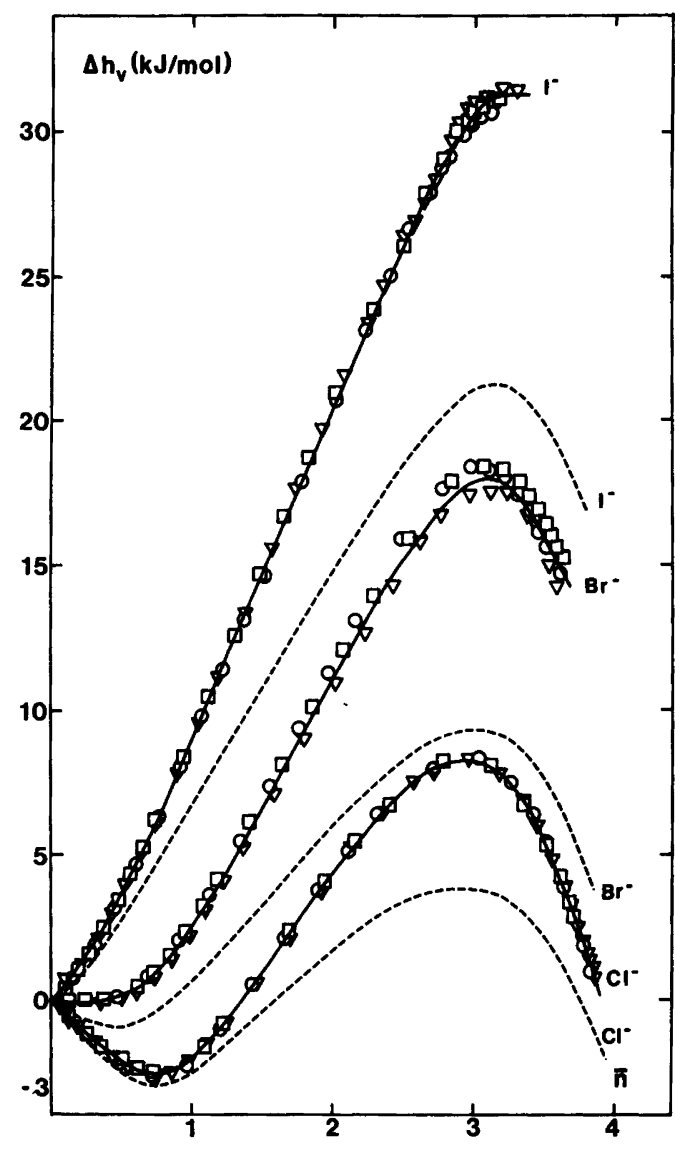

Fig. 4. The total molar enthalpy change $\Delta h_{\mathrm{v}}$ as a function of the ligand number $\bar{n}$ for the cadmium(II) chloride, bromide and iodide systems in DMSO, at $25^{\circ} \mathrm{C}$. The symbols refer to the present titrations in $0.1 \mathrm{M}$ ammonium perchlorate, at values of $C_{\mathrm{M}}^{\prime}$ stated in Fig. 3. The curves have been calculated for $0.1 \mathrm{M}$ and $1 \mathrm{M}$ ammonium perchlorate (solid and dashed, respectively), as described in Fig. 3.

An attempt to determine calorimetrically, by adding lithium halide solutions to ammonium perchlorate, the stability of the ammonium halide complexes did not give coherent results. The reason might well be that $\mathrm{NH}_{4}^{+}$and $\mathrm{Li}^{+}$act rather differently as medium cations, as will be shown in the next paper of this series. ${ }^{21}$

The complex formation postulated follows the order of increasing electrostatic interaction but already on account of the low charge density of $\mathrm{NH}_{4}^{+}$ a simple electrostatic interpretation seems hardly 
Table 5. Equilibrium constants $\left(K_{\mathrm{j}} / \mathrm{M}^{-1}\right)$ and thermodynamic functions $\left(\Delta G_{\mathrm{j}}^{\circ}, \Delta H_{\mathrm{j}}^{\circ} / \mathrm{kJ} \mathrm{mol}^{-1} ; \Delta S_{\mathrm{j}}^{0} / \mathrm{JK}^{-1}\right.$ $\mathrm{mol}^{-1}$ ) for the stepwise formation of cadmium(II) chloride, bromide and iodide complexes in DMSO at $25^{\circ} \mathrm{C}$.

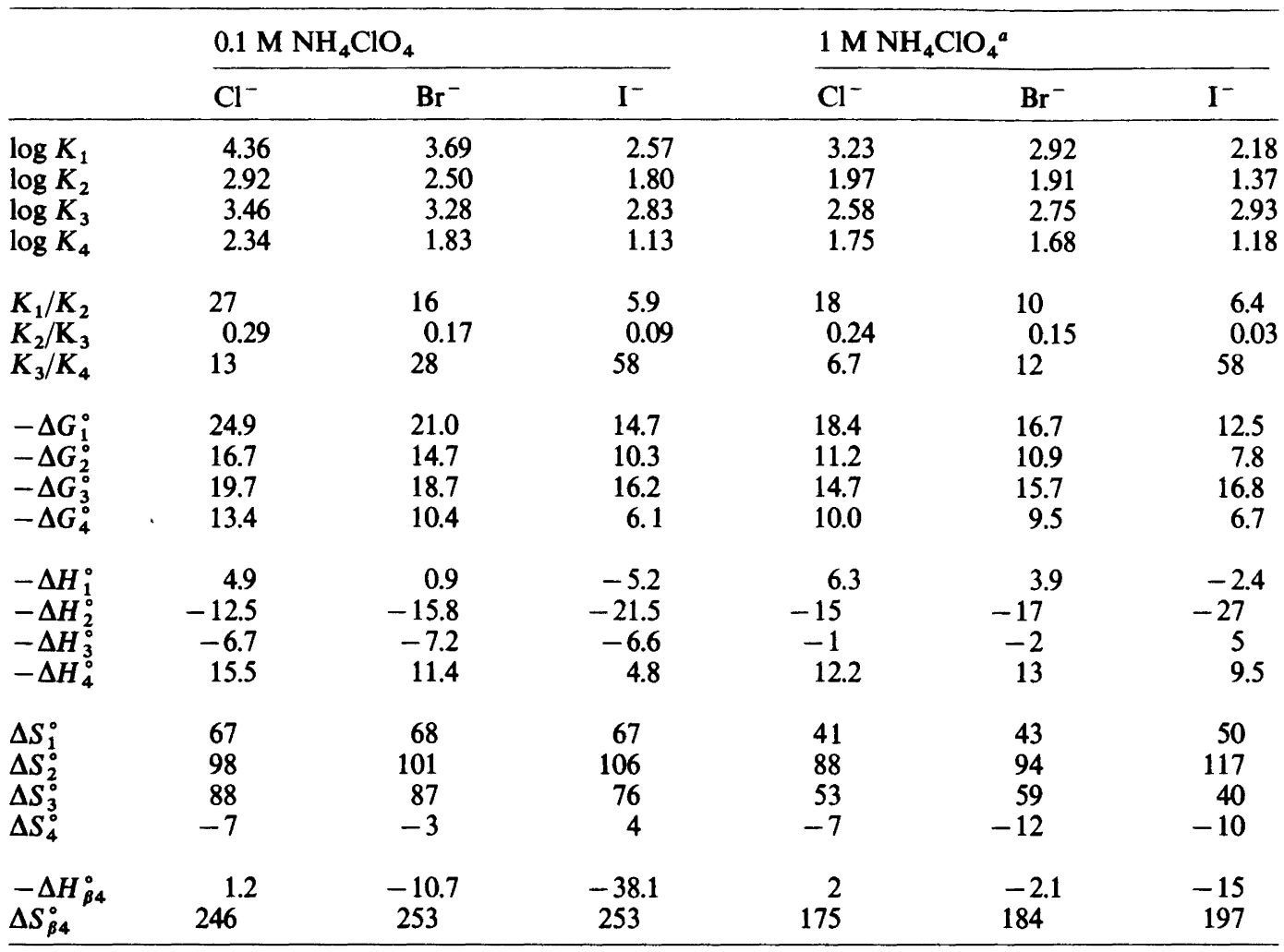

${ }^{a}$ Ref. 2.

sufficient. That such an interpretation is, in fact, wholly inadequate is shown by the behaviour of the cadmium(II) bromide system in lithium perchlorate media. ${ }^{21}$ Certainly, the complex formation in DMSO between $\mathrm{NH}_{4}^{+}$and halide ions is mainly due to the hydrogen bonding properties of the ligands. In an aprotic solvent where no better partners are available, $\mathrm{NH}_{4}^{+}$will participate in those hydrogen bonds which in a protic solvent such as water would be formed between $\mathrm{Cl}^{-}$, or $\mathrm{Br}^{-}$, and the solvent molecules.

A comparison of the values of $\Delta H_{\beta 4}^{\circ}$ and $\Delta S_{\beta 4}^{\circ}$ shows that the overall stability increase between the two $\mathrm{NH}_{4}^{+}$media is very much an entropy effect, see Table 5. A general increase of the entropy gain as $I$ decreases is certainly to be expected from the circumstance that a lower concentration of $\mathrm{NH}_{4}^{+}$ means less order in the bulk solvent. The desolvation accompanying the formation of cadmium(II) halide complexes will then result in a larger total loss of order, and hence in a more favourable entropy.

Such an increase of the entropy gain is generally accompanied by a less favourable enthalpy change, as part of the energy gained by solvation of medium ions is lost when $I$ decreases. As to the present systems, this partial compensation is prominent in the case of the iodide. To some extent it also occurs for the bromide, while for the chloride the value of $\Delta H_{\beta 4}^{\circ}$ is much the same in both media. This may be rationalized by postulating that in $1 \mathrm{M} \mathrm{NH}_{4}^{+}$medium extensive reactions involving $\mathrm{Cl}^{-}$, and $\mathrm{Br}^{-}$, take place which make the values of $\Delta H_{\beta 4}^{\circ}$ less favourable than they would otherwise be. Most likely, these reactions are the dissociations of $\mathrm{NH}_{4} \mathrm{Cl}$, and $\mathrm{NH}_{4} \mathrm{Br}$, which accompany the formation of the cadmium complexes. As $\mathrm{NH}_{4} \mathrm{Cl}$ and $\mathrm{NH}_{4} \mathrm{Br}$ are 
formed much more extensively in $1 \mathrm{M}$ than in 0.1 $\mathrm{M} \mathrm{NH}_{4}^{+}$, the dissociation will be a more prominent reaction in the former medium.

On the whole, the values of $\Delta H_{j}^{\circ}$ and $\Delta S_{j}^{\circ}$ of the individual steps follow the same pattern though the picture is somewhat modified by changes in the relative magnitudes. In both media, the values of $\Delta S_{2}^{\circ}$ are the most favourable of all $\Delta S_{\mathrm{j}}^{\circ}$ and those of $\Delta H_{2}^{\circ}$ the most unfavourable of all $\Delta H_{\mathrm{j}}^{\circ}$. The values of $\Delta S_{3}^{\circ}$ and $\Delta H_{3}^{\circ}$ are much larger in $0.1 \mathrm{M}$ than in $1 \mathrm{M}$ medium, however.

Already at a time when the octahedral structure of the solvated $\mathrm{Cd}^{2+}$, and the tetrahedral structure of the finally formed $\mathrm{CdX}_{4}^{2-}$ were only reasonable postulates, the very high values of $\Delta H_{2}^{\circ}$ and $\Delta S_{2}^{\circ}$ in DMSO were interpreted as indicating a switch from octahedral to tetrahedral coordination at the formation of $\mathrm{CdX}_{2}$. Later on, the structures postulated for the initial solvate and the final tetrahalide complex have been fully confirmed by direct determination of their structures by $\mathrm{X}$-ray diffraction. ${ }^{8,16}$ That the switch mainly takes place at the second step in DMSO has also been recently confirmed, and moreover both by nuclear magnetic resonance measurements ${ }^{22}$ and by studies of the $\mathrm{Cd}(\mathrm{II}) / \mathrm{Cd}(\mathrm{Hg})$ electrode kinetics ${ }^{23}$ in halide solutions. In the NMR spectra, large increases of the ${ }^{113} \mathrm{Cd}$ chemical shifts are found between the first and the second complex for all the halide systems, clearly indicating that the second step involves an abrupt change of coordination. As to the electrode kinetics, iodide and bromide, but not chloride complexes, participate in the charge transfer reaction. The different behaviour is presumably due to the circumstance that the larger halide ions are able to form bridges between the electrode and the divalent cadmium in solution. For those systems where the halide complexes do participate in the reaction, the rate of the charge

Table 6. Equilibrium constants $\left(K_{\mathrm{j}} / \mathrm{M}^{-1}\right)$ and thermodynamic functions $\left(\Delta G_{\mathrm{j}}^{\circ}, \Delta H_{\mathrm{j}}^{\circ} / \mathrm{kJ} \mathrm{mol}^{-1} ; \Delta S_{\mathrm{j}}^{\circ} / \mathrm{JK}^{-1}\right.$ $\mathrm{mol}^{-1}$ ) for the stepwise formation of zinc(II), cadmium(II) and mercury(II) bromide complexes in DMSO at $25^{\circ} \mathrm{C}$.

\begin{tabular}{|c|c|c|c|c|c|c|}
\hline & \multicolumn{3}{|c|}{$0.1 \mathrm{M} \mathrm{NH}_{4} \mathrm{ClO}_{4}$} & \multicolumn{3}{|c|}{$1 \mathrm{M} \mathrm{NH}_{4} \mathrm{ClO}_{4}{ }^{a}$} \\
\hline & $\mathrm{Zn}^{2+}$ & $\mathrm{Cd}^{2+}$ & $\mathrm{Hg}^{2+}$ & $\mathrm{Zn}^{2+}$ & $\mathrm{Cd}^{2+}$ & $\mathrm{Hg}^{2+}$ \\
\hline $\begin{array}{l}\log K_{1} \\
\log K_{2} \\
\log K_{3} \\
\log K_{4}\end{array}$ & $\begin{array}{l}1.86 \\
3.31 \\
1.98\end{array}$ & $\begin{array}{l}3.69 \\
2.50 \\
3.28 \\
1.83\end{array}$ & $\begin{array}{r}12.92 \\
9.05 \\
5.66 \\
2.60\end{array}$ & $\begin{array}{l}0.85 \\
2.89 \\
1.35\end{array}$ & $\begin{array}{l}2.92 \\
1.91 \\
2.75 \\
1.68\end{array}$ & $\begin{array}{r}12.14 \\
8.06 \\
5.14 \\
2.54\end{array}$ \\
\hline $\begin{array}{l}K_{1} / K_{2} \\
K_{2} / K_{3} \\
K_{3} / K_{4}\end{array}$ & $\begin{array}{l}0.04 \\
21\end{array}$ & $\begin{array}{c}16 \\
0.17 \\
28\end{array}$ & $\begin{array}{l}7.5 \times 10^{3} \\
2.4 \times 10^{3} \\
1.2 \times 10^{3}\end{array}$ & $\begin{array}{l}0.09 \\
35\end{array}$ & $\begin{array}{l}10 \\
0.15 \\
12\end{array}$ & $\begin{array}{l}1.2 \times 10^{4} \\
8.3 \times 10^{2} \\
4.0 \times 10^{2}\end{array}$ \\
\hline $\begin{array}{l}-\Delta G_{2}^{\circ} \\
-\Delta G_{2}^{\circ} \\
-\Delta G_{3}^{\circ} \\
-\Delta G_{4}^{\circ}\end{array}$ & $\begin{array}{l}10.6 \\
18.9 \\
11.3\end{array}$ & $\begin{array}{l}21.0 \\
14.2 \\
18.7 \\
10.4\end{array}$ & $\begin{array}{l}73.7 \\
51.6 \\
32.3 \\
14.8\end{array}$ & $\begin{array}{r}4.8 \\
16.5 \\
7.7\end{array}$ & $\begin{array}{r}16.7 \\
10.9 \\
15.7 \\
9.5\end{array}$ & $\begin{array}{l}69.3 \\
46.0 \\
29.3 \\
14.5\end{array}$ \\
\hline $\begin{array}{l}-\Delta H_{1}^{\circ} \\
-\Delta H_{2}^{\circ} \\
-\Delta H_{3}^{\circ} \\
-\Delta H_{4}^{\circ}\end{array}$ & $\begin{array}{r}-22.3 \\
-19.9 \\
5.9\end{array}$ & $\begin{array}{r}0.9 \\
-15.8 \\
-7.2 \\
11.4\end{array}$ & $\begin{array}{l}20.0 \\
24.1 \\
24.4 \\
17.3\end{array}$ & $\begin{array}{r}-27.8 \\
-9.1 \\
4.2\end{array}$ & $\begin{array}{c}3.9 \\
-17 \\
-2 \\
13\end{array}$ & $\begin{array}{l}24.7 \\
31.9 \\
27.8 \\
19.1\end{array}$ \\
\hline $\begin{array}{l}\Delta S_{1}^{\circ} \\
\Delta S_{2}^{\circ} \\
\Delta S_{3}^{\circ} \\
\Delta S_{4}^{\circ}\end{array}$ & $\begin{array}{r}110 \\
130 \\
18\end{array}$ & $\begin{array}{r}68 \\
101 \\
87 \\
-3\end{array}$ & $\begin{array}{r}180 \\
92 \\
26 \\
-8\end{array}$ & $\begin{array}{r}110 \\
85 \\
12\end{array}$ & $\begin{array}{r}43 \\
94 \\
54 \\
-12\end{array}$ & $\begin{array}{r}149 \\
47 \\
5 \\
-16\end{array}$ \\
\hline $\begin{array}{l}-\Delta H_{\beta 3}^{\circ} \\
\Delta S_{\beta 3}^{\circ}\end{array}$ & $\begin{array}{c}-36.3 \\
258\end{array}$ & $\begin{array}{l}-22.1 \\
256\end{array}$ & $\begin{array}{l}68.5 \\
298\end{array}$ & $\begin{array}{c}-32.7 \\
207\end{array}$ & $\begin{array}{r}-15 \\
196\end{array}$ & $\begin{array}{l}84.4 \\
201\end{array}$ \\
\hline
\end{tabular}

${ }^{a}$ Refs. $4\left(\mathrm{Zn}^{2+}\right), 2\left(\mathrm{Cd}^{2+}\right)$ and $5\left(\mathrm{Hg}^{2+}\right)$. 
transfer increases tremendously between the first and the second step. The complexes $\mathrm{CdBr}_{2}$ and $\mathrm{CdI}_{2}$ thus give large contributions to the exchange current which can be correlated with the change of coordination taking place at their formation. The close connection between values of $\Delta H_{j}^{\circ}$ and $\Delta S_{j}^{\circ}$, and the rate of the charge transfer, is further demonstrated by results found for the cadmium thiocyanate complexes. Contrary to what has been found for the halides, the values of $\Delta H_{2}^{\circ}$ and $\Delta S_{2}^{\circ}$ are both quite small, indicating that in the thiocyanate system no drastic change of coordination takes place at the second step. ${ }^{2}$ In consistency with this, the rate of the charge transfer due to $\mathrm{Cd}(\mathrm{SCN})_{2}$ is quite low. ${ }^{24}$

The circumstance that $\Delta S_{3}^{\circ}$ and $\Delta H_{3}^{\circ}$ are much larger relative to $\Delta S_{2}^{\circ}$ and $\Delta H_{2}^{\circ}$ in $0.1 \mathrm{M}$ than in $1 \mathrm{M}$ $\mathrm{NH}_{4}^{+}$medium (Table 5), means that the change of coordination is less clear-cut in the more dilute medium. In this case, the switch seemingly extends over two steps which would imply that the second step exists as both octahedral and tetrahedral coordination isomers.

For the zinc(II) and mercury(II) bromide complexes, similar increases of stability occur between 1 $\mathrm{M}$ and $0.1 \mathrm{M} \mathrm{NH}_{4}^{+}$medium as in the case of the cadmium(II) bromide (Table 6). This proves, of course, that they are due to the ligand and not to the metal ion involved, just as has been implied in the reasoning above.

As only three complexes are formed in the zinc system, $\Delta H_{\beta 3}^{\circ}$ and $\Delta S_{\beta 3}^{\circ}$ must be used for the comparison of the overall thermodynamics. As the switch to tetrahedral coordination has by then taken place not only for $\mathrm{Hg}$ (II) and $\mathrm{Cd}(\mathrm{II})$, but also for $\mathrm{Zn}(\mathrm{II}), c f$. below, the exclusion of the last step does not matter very much, however. The picture emerging is very similar for all the systems. A considerable increase of $\Delta S_{\beta 3}^{\circ}$ from $1 \mathrm{M}$ to $0.1 \mathrm{M}$ medium is partly compensated by more unfavourable values of $\Delta H_{\beta 3}^{\circ}$. It should be noted, however, that both effects are markedly larger for $\mathrm{Hg}$ (II) than for $\mathrm{Cd}(\mathrm{II})$ and, especially, $\mathrm{Zn}$ (II). In consideration of the huge differences in strength and nature of the complexes, these differences in behaviour seem indeed modest.

For the zinc(II) bromide system, the relative size of $\Delta S_{1}^{\circ}$ and $\Delta S_{2}^{\circ}$ changes between $1 \mathrm{M}$ and $0.1 \mathrm{M}$ medium (Table 6). The tendency found already for the cadmium(II) systems, that the switch to tetrahedral coordination occurs at a later stage as the concentration of medium ions decreases, is thus so marked for zinc(II) bromide that the step of the main switch really changes. Considering that a higher concentration of medium ions ought to encourage the extra desolvation of the metal ion accompanying the change of coordination, it seems natural that the change should tend to occur at an earlier stage in the more concentrated medium, as is in fact the case. For the zino(II) bromide system, the change from $1 \mathrm{M}$ to $0.1 \mathrm{M}$ medium means that its behaviour starts to resemble that found for the iodide and thiocyanate system already in $1 \mathrm{M}$ medium. ${ }^{4}$

For the zinc(II) bromide system, the coordination change postulated from the thermodynamic data cannot be confirmed by studies of the kinetics of the $\mathrm{Zn}(\mathrm{II}) / \mathrm{Zn}(\mathrm{Hg})$ electrode, as the bromide complexes do not participate in the charge transfer. ${ }^{25}$

Acknowledgements. Our thanks are due to Professor Roberto Portanova, University of Palermo, who performed part of the potentiometric titrations on the cadmium(II) systems. We gratefully acknowledge the support given to this project by the Swedish Natural Science Research Council.

\section{REFERENCES}

1. Ahrland, S. and Björk, N. O. Acta Chem. Scand. A 30 (1976) 249.

2. Ahrland, S. and Björk, N. O. Acta Chem. Scand. A 30 (1976) 257.

3. Ahrland, S. and Björk, N. O. Acta Chem. Scand. A 30 (1976) 265.

4. Ahrland, S., Björk, N. O. and Portanova, R. Acta Chem. Scand. A 30 (1976) 270.

5. Ahrland, S., Persson, I. and Portanova, R. Acta Chem. Scand. A 35 (1981) 49.

6. Cristensen, J. J., Ruckman, J., Eatough, D. J. and Izatt, R. M. Thermochim. Acta 3 (1972) 203.

7. Ahrland, S. and Björk, N. O. Acta Chem. Scand. A 28 (1974) 823.

8. Sandström, M., Persson, I. and Ahrland, S. Acta Chem. Scand. A 32 (1978) 607.

9. Persson, H. Acta Chem. Scand. 24 (1970) 3739.

10. Ahrland, S. and Persson, I. Acta Chem. Scand. A 34 (1980) 645.

11. Karlsson, R. and Kullberg, L. Chem. Scr. 9 (1976) 54; personal communication (for EMK).

12. Fronaus, S. In Jonassen, H. B. and Weissberger, A., Eds., Technique of Inorg. Chem., Interscience, New York, London 1963, Vol. 1, Chapter 1.

13. Ahrland, S., Chatt, J., Davies, N. R. and Williams, A. A. J. Chem. Soc. (1958) 264.

14. Grenthe, I., Ots, H. and Ginstrup, O. Acta Chem. Scand. 24 (1970) 1067.

15. Ots, H. Acta Chem. Scand. 26 (1972) 3810. 
16. Pocev, S., Triolo, R. and Johansson, G. Acta Chem. Scand. A 33 (1979) 179.

17. Sandström, M. Acta Chem. Scand. A 32 (1978) 627.

18. Ahrland, S., Hansson, E., Iverfeldt, $\AA$. and Persson, I. Acta Chem. Scand. A 35 (1981). In press.

19. Gerding, P. and Jönssön, I. Acta Chem. Scand. 22 (1968) 2247.

20. Ahrland, S. and Björk, N. O. Coord. Chem. Rev. $16(1975) 115$.

21. Ahrland, S. and Persson, I. Acta Chem. Scand. A 35 (1981). In press.

22. Drakenberg, T., Björk, N.-O. and Portanova, R. J. Phys. Chem. 82 (1978) 2423.

23. Fronæus, S., Johansson, C. L. and Palm, B. J. Electroanal. Chem. 88 (1978) 1.

24. Fronzeus, S. and Palm, B. Acta Chem. Scand. A 32 (1978) 909.

25. Fronæus, S. and Johansson, C. L. J. Electroanal. Chem. 80 (1977) 283.

Received August 12, 1980. 